\title{
A TESSITURA DIALÓGICA EM PÔSTERS FORA TEMER
}

\author{
THE DIALOGICAL TEXTURE IN POSTERS FORA TEMER
}

\begin{abstract}
Antonio Flávio Ferreira de Oliveira ${ }^{63}$
RESUMO: Esta pesquisa investiga a tessitura dialógica em pôsteres fora temer. Para tanto, apoiamo-nos na problemática de: como se constitui a composição de sentido nesse gênero? A questão de pesquisa nos dá suporte para estabelecer o objetivo que cumpre investigar, pela Teoria Dialógica da Linguagem (TDL), a construção da enunciação e a rede de sentidos no gênero em questão. Elegemos, como suporte teórico, a Análise Dialógica do Discurso (ADD), estabelecida pelos fundamentos da TDL preconizada pelos estudos do Círculo de Bakhtin, preferencialmente por aqueles desenvolvidos por Bakhtin $(2010$; 2011; 2015) e Volochínov (2013). Metodologicamente, este trabalho está estabelecido pelos seguintes elementos: (1) a pesquisa tem a natureza qualitativo-interpretativista; (2) o corpus é constituído por três pôsteres relacionados ao tema proposto. As análises indicam que a composição dialógica dos pôsteres é construída pela luta entre as valorações que compreendem o todo axiológico perpassado pelo atravessamento de temas sociais dispersos no tempo e pela maneira como as forças de enunciações do passado constituem sentidos nos discursos do presente e do futuro.
\end{abstract}

PALAVRAS-CHAVE: Teoria Dialógica da Linguagem. Pôsteres. Tessitura.

ABSTRACT: This research investigates the dialogical texture in fora temer posters. Thus, the problem is related to: how is constituted the composition of meanings in the proposed genre? The objective is to comprehend through Dialogical Language Theory (DLT) the enunciative construction and the texture of meanings. Theoretically, we used the Dialogical Discourse Analysis (DDA) basis, mainly those ones established by Bakhtin Circle: Bakhtin (2010; 2011; 2015) and Volochínov (2013). Methologically, this work is established by: (1) a qualitative and interpretative research; (2) a corpus constituted by three posters related to the proposed genre. The analyses point that the dialogical composition is constructed by the conflicts between the valorations that comprehend the axiological whole crossed by social themes dispersed in time and by the manner how the forces of past enunciations constitute meanings in thepresent and future discourses.

KEYWORDS: Dialogical language theory. Posters. Textures.

\section{Introdução}

Esta pesquisa investiga os elementos dialógicos natessitura de pôsteres com a temáticaforatemer. Desse modo, a nossa prioridade foca nas questões referentes a como e a que elementos ideológicos, históricos, dentre outros, são estabelecidos naprodução de enunciados, para produzir múltiplos efeitos de sentido no imaginário social de uma coletividade.

A escolha desse tema se justifica pelo fato de, na sociedade hodierna, estar sendo produzidos enunciados referentes às questões políticas e sociais que abrangem a possiblidade de rejeição de um presidente da República Federativa Brasileira. Assim, esses enunciados refletem a composição de elementos que ecoam sobre diversos pontos de vista históricos e ideológicos da conjuntura da política nacional e isso constituiextrema relevância para a nossa investigação, haja vista compreendermos que essas valorações servem de base para a composição de sentidos na construção dos pôsteres.

Para dar sentido investigativo a esta pesquisa, apoiamo-nos no questionamento que estabelece a seguinte problemática: como se constitui a composição de sentido nesse gênero?Essa pergunta se contextualiza,devido ao fato de abordarmos sobre o complexo de vozes sociais que tecem os pôsteres escolhidos, razão pela qual acreditamos que essas vozes são os elementos essenciais para estabelecer a composição de um enunciado.Dessa maneira, a questão de pesquisa nos dá suporte para estabelecer o objetivo que cumpre investigar, pela

${ }^{63}$ Doutorando em Linguística pelo Programa de Pós-Graduação em Linguística da Universidade Federal da Paraíba. Endereço eletrônico: flavioccaa@hotmail.com 
TDL, como se estabelece a construção da enunciação e a produção discursivano gêneroreferente à temática.

Uma vez que pretendemos abordar fatos sociais materializados em palavras e em imagens, priorizamos os elementos conceituais da Análise Dialógica do Discurso (ADD), estabelecida pelos fundamentos da TDL, preconizada pelos estudos do Círculo de Bakhtin, preferencialmente por aqueles desenvolvidos por Bakhtin $(2010 ; 2011 ; 2015)$ e Volochínov (2013).

Metodologicamente, este trabalho está construído pela composição dos seguintes elementos: (1) a pesquisa tem natureza qualitativo-interpretativista; (2) tem um corpus constituído de três pôsteres relacionados ao tema foratemer; (3) a escolha dos pôsteresse deu haja vista sua recorrência nas redes sociais, bem como pela composição estabelecida por palavras e imagens; (4) o procedimento de análise foi feito da seguinte maneira: (A) foi feita a descrição dos elementos da cena enunciativa; e (B) a partir da descrição, foram relacionados e contrastados os elementos descritos às categorias conceituais da TDL, para gerar uma explicação e estabelecer resultados.

A pesquisa está organizada em duas seções: (A) a primeira, relacionada a uma discussão sobre os elementos conceituais da TDL; e (B) a segunda, que apresenta a análise dos fatos sociais referentes aos enunciados.

\section{Tessitura dialógica: elementos constitutivos}

A produção de linguagem dos sujeitos sociais está relacionada a todas as atividades que os seres humanos desempenham no cenário social. Assim, tudo o que se constrói nos campos das atividades humanas é refletido e refratado na e pela linguagem. De modo particular, a linguagem serve, ao homem, como um instrumento de interação, linguístico e semiótico, capaz de constituir o pensamento humano enquanto produto das ideologias que compreendem as diversas realidades da vida social. Nas palavras de Volochínov (2013, p. 141, grifos do autor), a linguagem se constitui como "o produto da atividade humana coletiva e reflete em todos os seus elementos tanto a organização econômica como a sociopolítica da sociedade que a gerou".

Tomando como base essa concepção de linguagem, principalmente no que tange à organização econômica e sociopolítica de uma sociedade, queremos tocar na questão do contexto em que está situado o Brasil da segunda década do ano dois mil.Desse modo, queremos afirmar que o cenário político brasileiro tem sido, hodiernamente, um espaço, no qual diversos conflitos têm surgido como resultado de atividades políticas, constituídas de valorações de imoralidade, no que diz respeito à administração pública. Dessa maneira, as diversas realidades que constituem o mundo político têm sido discursivizadas, pela mídia e por outrasinstituições que veiculam a informação como um complexo de enunciados capaz de criar, no imaginário do cidadão brasileiro, uma consciência na qual se instauram sentidos de revolta em relação aos posicionamentos de determinados grupos políticos.

Desse lugar de lutas axiológicas, surgem alguns posicionamentos pelos quais está sendo determinado o destino político do país. Dentre esses posicionamentos, de acordo com as enunciações de uma coletividade, sobre os fatos políticos da época, queremos apresentar os dois mais característicos: (1) o impeachment da ex-presidenta Dilma Rousseff, compreendido e enunciado, por certa parte da população, como um golpe de Estado; e (2) a atuação do presidente Michel Temer, enunciado como um governo marcado por práticas neoliberalistas,que têm por finalidade estabelecer diversas mudanças no cenário políticosocial, principalmente aquelas que afetam a garantia de direitos sociais adquiridos com a instauração da democracia e com a promulgação da Constituição Federal de 1988. Para sustentarmos esse posicionamento, usamoso aporte teórico e metodológico da TDL, para 
refletirmos sobre a constituição e a instauração dos fatos quecompreendem o cenário da política nacional.

Para iniciarmos, gostaríamos de abordar a concepção de horizonte social. Este, por sua vez, compreende um lugar socioideológicoonde são construídos os fatos relacionados aos pontos de vista das diversas realidades que refratam e refletem o cenário de um evento social. Nesse sentido, o processo de construção do mundo e dos seus eventos discursivos pode ser pensado a partir do que Geraldi (2013), enunciando os posicionamentos do Círculo de Bakhtin, estabelece. Veja:

Para construir o mundo, ninguém parte do nada! Sobre uma natureza encontrada, dada, operamos todos nós e jamais sozinhos: é preciso pensar que sobre ela atuam outros seres com que compartilhamos a vida. Mas, entre estes, somente nós "elaboramos" o mundo, pois the damos sentidos, jamais dados, jamais acabados, jamais prontos, jamais definidos(GERALDI,2013, p. 7, grifos do autor).

Em relação a essa citação, podemos compreender que a construção de um fato social se estabelece pela soma de pontos de vista que circulam em um dado campo social. Assim, podemos presumir que nada se constrói de modo isolado, pela imposição do pensamento de uma única consciência, mas, de modo peculiar, pela soma de pensamentos diversos que advêm dos pontos de vista de uma coletividade que constitui o todo do imaginário de uma comunidade. Esse construto coletivo fundamenta o repertório social de posicionamentos históricos, axiológicos, culturais, políticos, religiosos, econômicos, dentre outros, que formam a base para a compreensão individual e para a manifestação de um pensamento particular formado pela força constitutiva dos pensamentos da coletividade. Particularmente, isso acontecede modo irreiterável, pois a enunciação de um ponto de vista já dito ganha outras camadas de sentidos, pelo simples ato entoacional deum sujeito que, ao dar autoria e ao entoar enunciações de outrem, arquiteta o seu próprio ponto de vista.

Sobre o aspecto que instaura a entonação, podemos afirmar que isso está relacionado à maneira particular como um determinado sujeito impregna sua própria voz de outras vozes sociais, de vozes que servem como base para compor o repertório social de vozes. De acordo com o que afirma Volochínov (2013), o teor entoacional estabelece que:

Todas as enunciações se construirão precisamente com base em sua visão; suas possíveis opiniões e valorações determinarão a ressonância interna ou externa da voz - a entonação - e a escolha das palavras e sua composição numa enunciação concreta(VOLOCHÍNOV, 2013, p. 166, grifos do autor).

A entonação, a escolha e a composição das palavras servem de base para que um determinado sujeito enuncie concretamente, tendo em vista os elementos que estão no exterior do núcleo linguístico da palavra. Sobre esses elementos, o autor supracitado declara que:

A palavra na vida, com toda evidência, não se centra em si mesma. Surge da situação extraverbal da vida e conserva com ela o vínculo mais estreito. E mais, a vida completa diretamente a palavra, que não pode ser separada da vida sem que perca seu sentido(VOLOCHÍNOV, 2013, p. 77).

A partir desse exposto, podemos entender que os elementos que formam a concretude de uma palavra estão relacionados ao todo da vida na qual se funda essa palavra, elementos que são oriundos dos processos históricos e axiológicos, dos quais, à palavra, se incorporam elementos de ordem social, ou seja, elementos capazes de deformar a palavra em sua totalidade e conferi-la diversas possibilidades de sentidos, colocando-a no campo infinito de flutuações e mobilizações. 
$\mathrm{O}$ aspecto de concretude da palavra se estabelece pelo fato de a materialidade linguística ser colocada em interação dentro de um campo contextual, ou seja, nas dependências de um lugar social, onde elementos de diversas ordens influenciam no processo de mobilização de sentidos. Isso acontece graças aos diversos conflitos de forças históricas que movimentam a palavra dentro de um contínuo temporal capaz de conduzi-la, ilimitadamente, na ordem do passado, do presente ou do futuro. Esse deslocamento convoca os sentidos mais recônditos, bem como aqueles que ainda estão por vir, ocasionando um processo dialógico caracterizado por forças determinadas pelo todo do espaço-temporal.

Em se tratando do processo de inacabamento de sentidos da palavra, Bakhtin (2011) expressa que:

\begin{abstract}
Não existe a primeira nem a última palavra, e não há limites para o contexto dialógico (este se estende ao passado sem limites e ao futuro sem limites). Nem os sentidos do passado, isto é, nascidos no diálogo dos séculos passados, podem jamais ser estáveis (concluídos, acabados de uma vez por todas): eles sempre irão mudar (renovando-se) no processo de desenvolvimento subsequente, futuro do diálogo. Em qualquer momento do desenvolvimento do diálogo existem massas imensas e ilimitadas de sentidos esquecidos, mas em determinados momentos do sucessivo desenvolvimento do diálogo, em seu curso, tais sentidos serão relembrados e reviverão em forma renovada (em novo contexto). Não existe nada absolutamente morto: cada sentido terá sua festa de renovação. Questão do grande tempo (BAKHTIN, 2011, p 420, grifos do autor).
\end{abstract}

Como podemos ver, na citação, o contexto dialógico se caracteriza por um grande complexo de ilimitações, principalmente no que diz respeito à retomada e à criação de elementos dialógicos marcados pela soma de enunciações que compreendem o repertório do imaginário social de uma dada comunidade. Assim, o conflito entre essas enunciações dispersas no tempo e no espaço fundamenta o aspecto mais caraterístico para estabelecer o processo de mobilização de sentidos da palavra. Nesse movimento de resistência e de adequação de forças de sentidos, a palavra se faz única, irreiterável, uma palavra constituída pela força do todo do processo histórico, o principal elemento de vivacidade na renovação de sentidos.

Os elementos dialógicos que constituem a palavra, conforme Bakhtin (2015), são estabelecidospelo conflito que instaura a mobilização de sentidos. Desse modo, o autor estabelece os elementos que constituem as diversas possibilidades de deslocamentos de sentidos. Veja a seguinte citação:

\footnotetext{
Ora, todo discurso concreto (enunciado) encontra o objeto para o qual se volta sempre, por assim dizer, já difamado, contestado, avaliado, envolvido ou por uma fumaça que o obscurece ou, ao contrário, pela luz de discursos alheios já externados a seu respeito. Ele está envolvido e penetrado por opiniões comuns, pontos de vista, avaliações alheias, acentos. O discurso voltado para o seu objeto entra nesse meio dialogicamente agitado e tenso de discursos, avaliações e acentos alheios, entrelaçase em suas complexas relações mútuas, funde-se com uns, afasta-se de outros, cruzase com terceiros; e tudo isso pode formar com fundamento o discurso, ajustar-se em todas as suas camadas semânticas, tornar complexa sua expressão, influenciar toda a sua feição estilística (BAKHTIN, 2015, p. 48, grifos do autor).
}

Nessa citação, podemos compreender que estão em jogo os elementos da tessitura dialógica, de modo peculiar, os elementos que corroboram para uma concepção de concretude do discurso. Dessa maneira, percebemos que a tessitura do discurso diverge do todo da formalidade linguística e converge para a concretude que congrega a acentuação de valores sobre a camada linguística. Assim, adialogicidade instaura e colore o discurso que se constitui pelo cruzamento de conteúdos temáticos. Esses, por sua vez, emanam dos feixes de lutas 
sociais representadas pelos posicionamentos avaliativos e valorativos do cerne dessas lutas. Sendo assim, a tessitura dialógica institui o discurso como uma instância que convoca os pontos de vista do outro, estabelecidos pelo jogo de respostas, feitas por enunciações dispersas no tempo e no espaço.

Em sentido mais restrito, esse meio dialogicamente agitado faz do discurso um complexo de camadas, que envolve a linguagem como um recurso linguístico-semiótico para a produção da atividade humana; um ponto de chegada e de partida das avaliações e das valorações dos sujeitos, como um conjunto de respostas às enunciações já ditas;um lugar concreto para o entrelaçamento, a contestação, a fusão e o ajustamento de temas sociais imbricados nas muitas vozes que constituem o repertório do imaginário de uma coletividade.

O discurso configura a valoração e a avaliação de temas sociais. Assim, asunidades linguístico-semióticassão estabelecidas e são determinados os elementos para a constituição do enunciado, acarretando, para a concretização deste, valorações relacionadas à vida, à ideologia (que forma a consciência humana), à historicidade, ao tempo, ao espaço e às responsividades no intercâmbio das enunciações. Isso pode ser corroborado, de acordo com o queBakhtin (2015) expressa, quando afirma que:

O enunciado vivo, que surgiu de modo consciente num determinado momento histórico em um meio social determinado, não pode deixar de tocar milhares de linhas dialógicas vivas envoltas pela consciência socioideológica no entorno de um dado objeto da enunciação, não pode deixar de ser participante ativo do diálogo social. E disto que ele surge, desse diálogo, como sua continuidade, como sua réplica e não como se com ele se relacionasse à parte (BAKHTIN, 2015, p. 49).

A partir desse ponto vista, presumimos a ideia de que as avaliações e as valorações do outro constituem o elemento imprescindível para a constituição do dizer numa perspectiva ativa de interação.Dessa maneira, queremos sustentar esse posicionamento a partir das seguintes ideias: (1) "é como se no discurso estivesse encravada a réplica do outro que, digase de passagem, inexiste de fato, mas cuja ação provoca uma brusca reestruturação acentual e sintática do discurso" (BAKHTIN, 2010, p. 239); (2) "a replica do outro é inexiste, mas projeta sua sombra e deixa vestígios sobre o discurso, e essa sombra e esse vestígio são reais" (BAKHTIN, 2010, p. 239); (3) "qualquer plano de criação, qualquer ideia, sentimento ou emoção deve refratar-se através do meio constituído pela palavra do outro [...]" (BAKHTIN, 2010, p. 232).

A palavra alheiainstituios elementos de concretude que compõem o repertório do imaginário social. Essa palavra compreende o todo do dizer do sujeito que se faz interlocutor e que determina as avaliações e as entonações da voz do sujeito enunciador. De modo particular, a palavra do outro representa o componente ativo pelo qual se origina e se determina as atitudes responsivas. Assim, se é desse e para esse outro que surge e que vai a palavra, essa palavra constitui um lugar, um território comum, no qual se digladiam os temas sociais. Na verdade, a palavra institui o lugar do intercâmbio das vozes sociais. É a protagonista que se reveste de elementos contextuais, que muda de sentido a partir das entonações das diferentes bocas, a razão pela qual estabelece as atividades do ser humano. Em sentido mais específico, como aponta Bakhtin (2010):

A palavra não é um objeto, mas um meio constantemente ativo, constantemente mutável, de comunicação dialógica. Ela nunca basta a uma consciência, a uma voz. Sua vida está na passagem de boca em boca, de um contexto para outro, de um grupo social para outro, de uma geração para outra. Nesse processo ela não perde o seu caminho nem pode liberta-se até o fim do poder daqueles contextos concretos que integrou (BAKHTIN, 2010, p. 234). 
Uma característica importante que deve ser apresentada é que a força ativa, que constitui a palavra em direção ao outro, deve ser estabelecida, além da orientação desse outro, pelos elementos contextuais que compreendem o cenário para que nasça a enunciação. Dentre os aspectos que constituem o contexto, podemos destacar: (1) "um horizonte espacial compartilhado por ambos os falantes (a unidade do visível: a casa, a janela, etc.)" (VOLOCHÍNOV, 2013, p. 78, grifos do autor); (2) "o conhecimento e a compreensão comum da situação, igualmente compartilhado pelos dois" (VOLOCHÍNOV, 2013, p. 78, grifos do autor); e (3) "a valoração compartilhada pelos dois, desta situação" (VOLOCHÍNOV, 2013, p. 78). Em relação a esses três elementos, podemos concluir que a construção de um contexto estabelece um lugar comum aos participantes de uma interação discursiva; um horizonte espacial (físico ou virtual) no qual os sujeitos refletem e refratam avalições comuns, bem como a compreensão de pontos de vista referentes ao sistema cognitivo desses sujeitos em relação à historicidade do cenário de uma dada enunciação.

\section{A dialogicidade em pôsteres foratemer}

Após termos abordado alguns dos principais elementos que constituem a tessitura dialógica do enunciado, queremos, agora, investigar como esses elementos compõem a tessitura dos pôsteres foratemer. De modo específico, queremos, nesse empreendimento analítico, compreender como acontecem as relações dialógicas, bem como essas relações estabelecem sentidos nos mencionados enunciados. Vejamos o Pôster 1:

\section{Pôster 1}

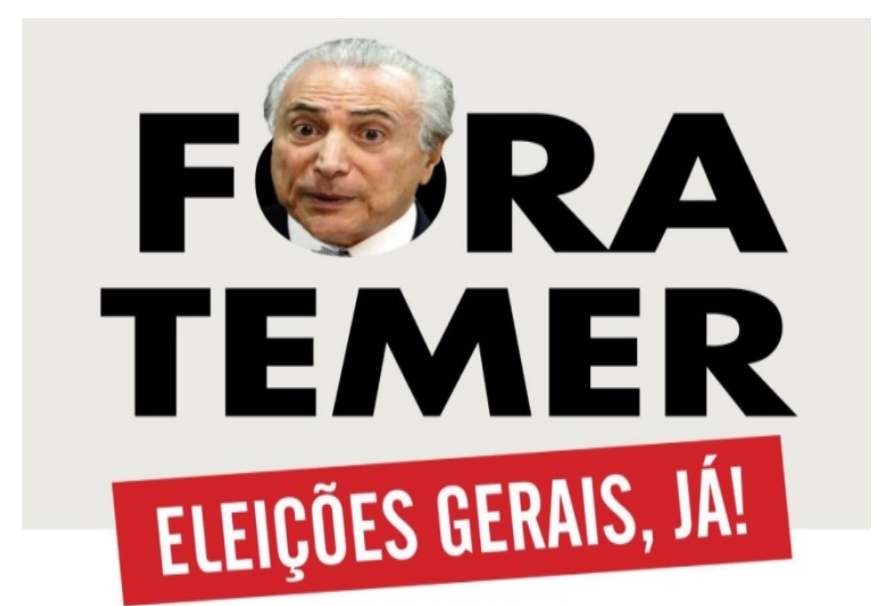

Sindicato dos
Metalúrgicos

https://blogdoherbert.com.br/2016/05/12/dilma-foi-afastada-vamos-as-ruas-pelo-fora-temer-e-todos-eles/

O Pôster 1 tem a arquitetônica estética composta por enunciados verbais e visuais. Desse modo, os primeiros estão representados por: (1) Fora Temer; (2) Eleições Gerais Já; e (3) Sindicato dos Metalúrgicos de São José dos Campos e Região. No caso do segundo componente, podemos ver, apenas, a face de Michel Temer, dentro do elemento linguístico (letra O), como se estivesse nos envoltos de um buraco; a imagem da face do presidente apresenta tonalidades de susto e desconfiança, como se ele estivesse sendo flagrado fazendo algo impróprio. 
No enunciado (1), podemos compreender que a tessitura dialógica se constitui a partir dos seguintes componentes:

(A) da produção da atividade coletiva de uma parte da população, que compreende a tomada de posse do Presidente Temer como um reflexo caracterizado por um golpe contra a democracia brasileira (haja vista à possibilidade de construção da falsificação do Impeachment da ex-presidenta Dilma Rousseff), razão pela qual, no campo sociopolítico, refratam sentidos de revolta em uma parte da representação social;

(B) da compreensão avaliativa de que a rejeição do Presidente Temer foi estabelecida pela determinação de um golpe de estado, de um todo axiológico que compôs diversas possibilidades de sentidos de rechaço;

(C) da constituição da palavra, composta das evidências axiológicas de uma classe caracterizada por valorações ideológicasinstauradas num cenário atravessado por atividades de manobras políticas;

(D) da enunciação da rejeição do Presidente Temer, como uma luta discursiva constituída deoutras enunciações de rejeição, surgidas no contexto político brasileiro do Impeachment do ex-presidente Fernando Collor, na década de 1980;

Nos Enunciados (2) e(3), podemos perceber que a composição da tessitura dialógica é constituída a partir dos seguintes componentes:

(A) da avaliação e da valoração das Eleições Gerais como uma possibilidade enunciativa emergida do passado (das Eleições Diretas de 1984), por fios de luz de discursos democráticos que, já externados, são penetrados por pontos de vista comuns para, na agitação da dialogicidade, dar um novo sentido ao movimento das Eleições Gerais;

(B) da dialogicidade que faz do Enunciado (2) um (re)construto histórico caracterizado pelos tons apreciativos do movimento do "golpe de estado" (de 1964), bem como do cruzamento ideológico que constitui a opinião comum da representação política do eleitorado da ex-presidenta Dilma Rousseff;

(C) das linhas dialógicas vivas que preenchem a palavra sindicato de sentidos históricos e ideológicos no que se refere à retomada das atividades sindicais;

(D) da orquestração de vozes histórico-ideológicas que ecoam no cenário da palavra sindicato, principalmente das valorações do todo que constituem as vozes que clamam pela defesa dos direitos sociais de uma classe (como por exemplo, as vozes do direito previdenciário e as vozes do ordenamento da organização do trabalho, etc.).

Por fim, em relação ao enunciado visual (as valorações gestuais da face de Michel Temer), podemos afirmar que encontramos tonalidades caracterizadas por: desconfiança, confusão edúvida. $\mathrm{O}$ todo de sentido nos tons da face do presidente estabelece, pelas atitudes responsivas, uma tessitura dialógica caracterizada por valorações constitutivas da falta de confiabilidade do povo na postura de governar do presidente, principalmente pelo fato de, uma parte desse povo, atribuir, como golpe, a posse de Temer.

Além disso, o todo de sentido estabelece um complexo de atitudes responsivas marcadas pela perplexidade e pela hesitação na face do presidente, razão pela qual, nesses enunciados visuais, instaura-sea tessitura dialógica composta de sentidos oriundos da luta de temas sociais que presumem a consciência popular de um governo golpista-absolutista e o seu complexo de atividades governamentais consideradas desdenhosas ao povo brasileiro. 


\section{Pôster 2}

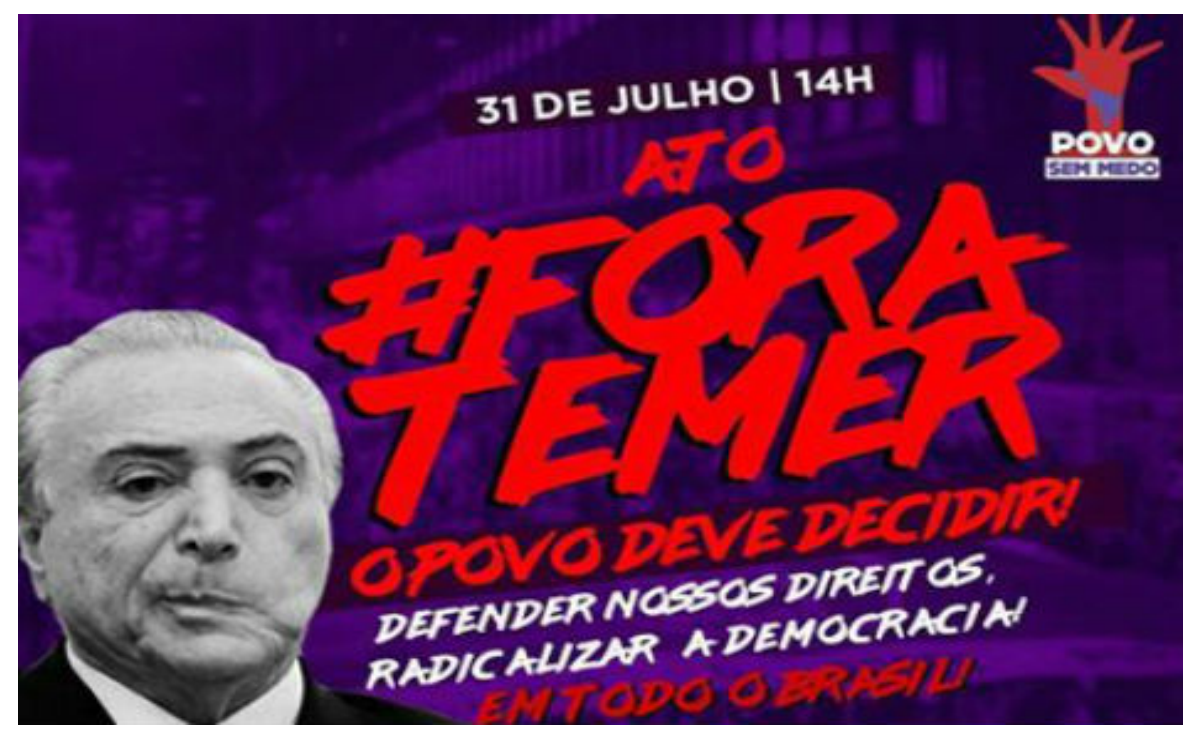

http://www.vermelho.org.br/noticia/284237-1

No Pôster 2, de modo geral, a tessitura dialógica se compõe, também, do jogo da harmonia de enunciados materializados em palavras e em imagem. Desse modo, os enunciados em palavras são: (1), 31 de julho / 14h; (2), ato \#fora Temer; (3), Povo sem medo; (4), o povo deve decidir; (5) Defender nossos direitos, radicalizar a democracia!; e (6) em todo o Brasil. Já no caso do enunciado imagético, temos: o rosto do presidente Temer, em preto e branco, palidamente, bem como gestos faciais de irritação, representados pelo entronchar de boca do presidente.

No enunciado (1), podemos compreender a representação do tempo, que marcará um evento popular caraterizado com ações populares em rejeição ao Presidente Temer. No (2), ato \#fora Temer, que, por sua vez, caracteriza a discursivização, nas redes sociais, da manifestação popular em oposição à posse e à atuação do presidente. No (3), Povo sem medo, podemos ver a enunciação da representação de uma nação (que [deveria] ter vez e voz), sendo colocada como uma força motriz capaz de enfrentar a pressão do presumido golpe político. No (4), o povo deve decidir, temos a enunciação que mostra o povo como a principal força na decisão da eleição de um presidente, bem como na decisão de escolha pelas práticas democráticas. No, (5), Defender nossos direitos, radicalizar a democracia!, podemos ver que, além da enunciação da defesa popular das bases democráticas, existe a enunciação do elemento de fixação, pela base popular, das garantias democráticas; e, por último, no (6), em todo o Brasil, o qual indica que a luta popular não é apenas de responsabilidade de uma ou de algumas regiões, mas de todas as regiões do país. No caso do enunciado imagético, que apresenta o entronchar de boca do presidente, podemos perceber os tons de indignação e de pouco caso do presidente, tanto no que diz respeito a ele não estar satisfeito com a revolta popular, quanto ao descaso, de sua parte, pela revolta do povo quanto ao seu exercício de governo.

Dito isso, compreendemos que o conjunto de enunciadosno Pôster 2compõea tessitura dialógica pelo estabelecimento defios de historicidade; pela retomada discursiva ([re]enunciação) dos atos populares em busca da democracia; pelo jogo de atitudes responsivas constituídas pelas vozes populares que ecoam sentidos de justiça social e de liberdade democrática; pela enunciação de elementos ideológicos que ecoamnas vozes jurídicas da Constituição Federal de 1988; bem como pela enunciação de o país ser representado, em uníssono, pelas vozes do povo de todas as regiões quanto aos atos democráticos garantidos na Carta Magna. 
A harmonia de sentidos estabelecida nos enunciados (1), (2), (3), (4), (5) e (6) gera uma atitude responsiva, no enunciado imagético, que representa a avaliação e a valoração do presidente, em resposta aos gritos populares. Nesse sentido, podemos compreender que o todo do Pôster 2 se tece, dialogicamente:

(A) por refletir a historicidade, as marcas temporais ditas e presumidas, de fatos sociais impregnados de temas históricos e ideológicos re(enunciados) em um acontecimento que refrata, deslizando no tempo, as condições para estabelecer sentidos pertinentes ao contexto da atual conjuntura política brasileira;

(B) pela valoração e pela avaliação da imagem do presidente, constituídas, num cenário de conflitos, pelos sentidos oriundos de fatos ocorridos no passado quanto à possibilidade de um golpe político;

(C) pela mobilização de contextos históricos referentes às práticas do golpe, bem como pelo complexo de vozes ideológicas que ecoam na unicidade democrática da voz do povo;

(D) pela retomada, nas imagens e nas palavras, de conteúdos ideológicos atravessados pelos atos de defesa e de perpetuação das bases democráticas;

(E) pela valoração da construção de verdade, feita na imagem de ilegitimidade de um presidente que assumiu seu posto em face de uma manobra considerada, por alguns, como(anti)democrática;

(F) pela enunciação das vozes populares em busca da construção de uma verdade instaurada pelas práticas e pelos atos das manifestações nas ruas do país - a legitimidade democrática.

\section{Pôster 3}

O Pôster 3 é composto por dois enunciados: (1) um enunciado imagético, que reflete a figura do presidente na figura do diabo; e o enunciado (2), \#foratemer, que diz respeito à convocação de protesto nas redes sociais.

Em relação à descrição do Pôster 3, podemos afirmar que a construção da tessitura dialógicaacontece pelo fato de os enunciados (1) e (2) refletirem sentidos pelos fios refratários da imagem de umafigura mitológica que representa a origem e a essência da maldade. Assim,considerando que a imagem, sozinha, não opera sentidos e que essa convocação de protesto nas redes sociais é determinada pela força de sentido da imagem, podemos afirmar que arelação de sentidos do pôster é construídapelo atravessamento de outras imagens que, numa escala de historicidade, formaram-se, axiologicamente, no imaginário social, impregnando-se de valores mitológicos, principalmente daqueles que se formam pela determinação do imaginário social religioso.

A partir desse exposto, podemos afirmar que, no todo do Pôster 3, a tessitura dialógica seconstitui pelos seguintes elementos:

(A) a mobilização de sentidos,que é feita pelo complexo de vozes mitológicas que ecoam os sentidos de maldade na figura do Diabo;

(B) os sentidos de maldade que, ao se formarem do complexo de vozes mitológicas, travam uma luta dialógica com os sentidos de maldade construídos pelas vozes da mídia sobre a figura do presidente, em relação à práticas políticas que põem em detrimento garantias fundamentais e direitos sociais do povo;

(C) a dialogicidade que, entre os elementos mitológicos da imagemeas atividades executivo-estatais do presidente, ganha sentidos graças ao jogo discursivo que serve de cenário para ecoar o conjunto de vozes referentes aos prejuízos demasiados à classe mais popular que existe no país; 
(D) as atividades estatais que ganham sentidos de maldade pelas valorações e pelas avaliações de sujeitos que representam uma classe desfavorecida por essas medidas, bem como pela valoração de autoritarismo das vozes que representam a bancada do presidente.

Através da relação entre as valorações de maldade advindas de uma figura mitológica do imaginário religioso-cristão e as enunciações de rejeição do presidente pelo povo, podemos constatar que, nesse complexo de imbricações de vozes e de lutas axiológicas, a tessitura do Pôster 3 se estabelece:pelo confronto dialógico entre o deslizamento de sentidos da imagem do presidente e a presunçãodo ser imaginário que foi enunciado; pelo efeito de valorações negativas em relação às práticas governamentais do presidente e as valorações do ser surrealanunciado na imagem; bem como pela harmonia entre a natureza do mal que origina a maldade humana e às práticas humanas centradas nas práticas institucionais, principalmente aquelas desprovidas de probidade em relação ao mando governamental e o respeito às garantias constitucionais estabelecidas pelo acordo e pela convenção democrática.

Em suma, nos pôsteres analisados, constatamos que a construção da tessitura dialógica foi estabelecida pela povoação de sentidos advindos do complexo de enunciações que foram dispersas, na irrupção do tempo, para constituir o todo que compõem o imaginário coletivo de uma sociedade. Desse modo, pudemos perceber que esses elementos axio-ideológicos se impregnam em materialidades linguísticas e visuais, para que, de modo particular, sejam produzidos os enunciados nos diversos eventos discursivos da interação humana nas múltiplas esferas sociais.

\section{Considerações finais}

Após termos analisado os fatos discursivos, temos a convicção de que atingimos o objetivo da nossa pesquisa, bem como cumprimos com o empreendimento de buscar possíveis respostas para o problema proposto. Dessa maneira, as análises apontam que os pôsteresforatemer se tecem dialogicamente a partir da seguinte conjuntura:

(1) pela existência de vozes ideológicas e históricas que vociferam sobre a luta de temas sociais que relacionam a posse do presidente ao reflexo e à refração de um golpe político à democracia brasileira;

(2) pela enunciação de elementos ideológicos que caracterizam uma compreensão avaliativa de rejeição ao presidente;

(3) pela impregnação, à palavra e à imagem, de evidências axio-ideológicas em vozes sociais com ecos de revolta e de nãoaceitação do presidente, devido ao fato de haver uma compreensão ativo-responsiva, por uma parte da sociedade, de sua tomada de poder ser fruto de possíveis manobras políticas;

(4) pelo jogo de lutas discursivasatravessadas de enunciações de rejeição, determinadas pelo contexto de Impeachment da ex-Presidenta Dilma Rousseff;

(5) pela orquestração de vozes socioidelógicas que fazem ecoar, no cenário da palavra e da imagem, a valoração da defesa de direitos sociais de uma classe desfavorecida na ordem da previdência e do trabalho;

(6) pela construção de valorações gestuais de dúvida, desconfiança, perplexidade e hesitação, na face do presidente, que tecem, dialogicamente, sentidos de luta entre temas sociais, bem como que estabelecem uma consciência social marcada pela oposição entre os pontos de vista populares e a valoração de um governo golpista. 


\section{REFERÊNCIAS}

BAKHTIN, Mikhail. Problema da poética de Dostoiévski. Rio de Janeiro: Forense Universitária, 2010.

. Estética da criação verbal. São Paulo: Martins Fontes, 2011.

. Teoria do romance I: a estilística. São Paulo: Editora 34, 2015.

DILMA FOI AFASTADA VAMOS AS RUAS PELO FORA TEMER E TODOS ELES.

Disponível em: <https://blogdoherbert.com.br/2016/05/12/dilma-foi-afastada-vamos-as-ruaspelo-fora-temer-e-todos-eles/> Acesso em: 09 ago. 2017.

GERALDI, João Wanderley. O mundo não nos é dado, mas construído. In: VOLOCHÍNOV, Valentin Nikolaevich. A construção da enunciação e outros ensaios. São Carlos: Pedro \& João Editores, 2013.

NOTÍCIA. Disponível em: <http://www.vermelho.org.br/noticia/284237-1> Acesso em: 09 ago. 2017.

VOLOCHÍNOV, Valentin Nikolaevich. A construção da enunciação e outros ensaios. São Carlos: Pedro \& João Editores, 2013.

Recebido em 02/08/2017

Aceito em 26/11/2017 